\title{
Review \\ Clinical review: Critical illness polyneuropathy and myopathy
} Greet Hermans ${ }^{1}$, Bernard De Jonghe ${ }^{2}$, Frans Bruyninckx ${ }^{3}$ and Greet Van den Berghe ${ }^{4}$

\author{
${ }^{1}$ Medical Intensive Care Unit, Department of General Internal Medicine, University Hospitals, Katholieke Universiteit Leuven, Herestraat 49, \\ B-3000 Leuven, Belgium \\ ${ }^{2}$ Réanimation Médico-chirurgicale, Centre Hospitalier de Poissy-Saint-Germain en Laye, Poissy, France, Rue du Champ Gaillard 10, F-78300 Poissy, \\ France \\ ${ }^{3}$ Department of Physical Medicine and Rehabilitation, University Hospitals, Katholieke Universiteit Leuven, Herestraat 49, B-3000 Leuven, Belgium \\ ${ }^{4}$ Department of Intensive Care Medicine, University Hospitals, Katholieke Universiteit Leuven, Herestraat 49, B-3000 Leuven, Belgium
}

Corresponding author: Greet Van den Berghe, greet.vandenberghe@uz.kuleuven.be

Published: 25 November 2008

This article is online at http://ccforum.com/content/12/6/238

(c) 2008 BioMed Central Ltd

Critical Care 2008, 12:238 (doi:10.1186/cc7100)

\begin{abstract}
Critical illness polyneuropathy (CIP) and myopathy (CIM) are major complications of severe critical illness and its management. CIP/ CIM prolongs weaning from mechanical ventilation and physical rehabilitation since both limb and respiratory muscles can be affected. Among many risk factors implicated, sepsis, systemic inflammatory response syndrome, and multiple organ failure appear to play a crucial role in CIP/CIM. This review focuses on epidemiology, diagnostic challenges, the current understanding of pathophysiology, risk factors, important clinical consequences, and potential interventions to reduce the incidence of CIP/CIM. $\mathrm{CIP} / \mathrm{CIM}$ is associated with increased hospital and intensive care unit (ICU) stays and increased mortality rates. Recently, it was shown in a single centre that intensive insulin therapy significantly reduced the electrophysiological incidence of CIP/CIM and the need for prolonged mechanical ventilation in patients in a medical or surgical ICU for at least 1 week. The electrophysiological diagnosis was limited by the fact that muscle membrane inexcitability was not detected. These results have yet to be confirmed in a larger patient population. One of the main risks of this therapy is hypoglycemia. Also, conflicting evidence concerning the neuromuscular effects of corticosteroids exists. A systematic review of the available literature on the optimal approach for preventing CIP/CIM seems warranted.
\end{abstract}

\section{Introduction}

Critical illness polyneuropathy (CIP), first described by Bolton and colleagues in 1986 [1], is a frequent complication of critical illness, acutely and primarily affecting the motor and sensory axons. This disorder can cause severe limb weakness and prolonged weaning. Several reports of severely ill patients with muscle wasting and polyneuropathy already existed by the end of the 19th century. Improvement of diagnostics later on revealed that muscle may be primarily involved, which is called myopathy in critical illness or critical illness myopathy (CIM) [2-5]. The condition has also been described in children [6].

\section{Clinical signs and diagnosis}

CIP and CIM share the major clinical sign of flaccid and usually symmetrical weakness. Other clinical signs include the reduction in or absence of deep tendon reflexes [7-9]. Patients with CIP may show a distal loss of sensitivity to pain, temperature, and vibration. Although facial muscles are relatively spared, they can be involved and ophthalmoplegia may occur, although it is very rare $[1,7,9]$. Weaning problems are ascribed to the involvement of the phrenic nerves and the diaphragm, and intercostal and other accessory respiratory muscles can be affected as well $[1,10]$. It should be noted that CIP represents the response of the peripheral nervous system to critical illness, but the central nervous system also is frequently affected by critical illness, manifesting as a diffuse encephalopathy that occurs very early in the process [11].

Currently, several investigators use the Medical Research Council (MRC) sum score as a screening tool for CIP/CIM [12]. This score evaluates muscle force on a scale from 0 to 5 in three muscle groups of both upper and lower limbs, rendering a maximum score of 60 . $\mathrm{CIP} / \mathrm{CIM}$ is arbitrarily diagnosed if the MRC sum score is less than 48 [12]. Though originally developed for and validated in patients with Guillain-Barré syndrome [13], this score is very interesting as it reflects actual limb muscle force. However, a limitation of this score is that it reflects only weakness, without pointing out its cause. Also, patients need to be cooperative. Therefore, the MRC sum score can be used only after awakening (for example, at the onset of weaning from mechanical ventilation). As for any voluntary manoeuvre in the intensive

$\mathrm{ARDS}=$ acute respiratory distress syndrome; $\mathrm{CIM}=$ critical illness myopathy $\mathrm{CIP}=$ critical illness polyneuropathy $\mathrm{CK}=\mathrm{creatine}$ kinase; $\mathrm{CMAP}=$ compound muscle action potential; $\mathrm{CS}=$ corticosteroids; $\mathrm{EMG}=$ electromyography; $\mathrm{ICU}=$ intensive care unit; $\mathrm{MICU}=$ medical intensive care unit; $\mathrm{MOF}=$ multiple organ failure; MRC = Medical Research Council; NMBA = neuromuscular blocking agent; SICU = surgical intensive care unit; $\mathrm{SIRS}=$ inflammatory response syndrome; SNAP = sensory nerve action potential; SR = sarcoplasmatic reticulum. 
care unit (ICU), satisfactory patient comprehension and cooperation should be evaluated and confirmed. Otherwise, overestimation of muscle weakness may occur [14].

Technical investigations can provide further evidence for CIP/CIM. These include serum measurements of muscle necrosis parameters (serum creatine kinase, CK), electromyography (EMG) and nerve conduction studies, and muscle biopsy. Serum CK levels are not very helpful since they are normal if muscle necrosis is absent or scattered, which commonly is the case. Even in patients with overt muscle necrosis, an increase in CK is often transient and can be missed. EMG and nerve conduction studies provide a bedside method to confirm the diagnosis and to exclude other neuromuscular causes of weakness, although routine electrophysiological examination oftentimes cannot discriminate between CIP and CIM in critically ill, sedated, uncooperative, or extremely weak patients [15]. In contrast to the MRC sum score mentioned above, it can be used before patients have recovered satisfactory consciousness and cooperation and therefore offers the advantage of identifying affected patients in an earlier stage. The first electrophysiological sign that can occur very early, even within 2 to 5 days after the onset of critical illness, is a reduction in amplitude of the nerve conduction potentials (compound muscle action potential (CMAP) or sensory nerve action potential (SNAP) or both) with preserved conduction velocity. Recent data showed that the majority of patients admitted for sepsis showed reduced nerve conduction amplitudes within 3 days of admission and that change of baseline nerve conduction response amplitude at 1 week was predictive for the development of acquired neuromuscular dysfunction [16]. The reduction in amplitudes often precedes the clinical findings as well as the accompanying fibrillation potentials and positive sharp waves that may not occur until the second or third week [17-19]. A multicentre prospective trial showed that electrophysiological screening using peroneal CMAP reduction below two standard deviations of the normal value accurately identifies patients with CIP/CIM [20]. Abnormal SNAPs are characteristic for CIP, although local oedema can interfere with optimal sensory nerve stimulation and recording. In addition, CIP and CIM often coexist. Electrophysiological differentiation between CIP and CIM is possible in the adequately awake and cooperative patient in whom voluntary motor unit potential recruitment can be obtained, in the rare case when the polyneuropathy is purely sensory [21], or using direct muscle stimulation. This shows reduced or absent action potentials in the case of CIM, reflecting loss of muscle electrical excitability, in contrast with normal values in CIP [22-24]. However, this technique requires an experienced examiner in order to obtain reliable results. As routine electrophysiological examination in critically ill patients frequently cannot differentiate between neuropathy and myopathy $[15,25]$, muscle biopsy can be performed and is considered a gold standard for the involvement of muscles in the disease process. Percutaneous muscle biopsy is relatively easy and can be performed at the bedside. Determination of the myosin/actin ratio has been suggested for rapid diagnosis of myopathy [26]. The clinical relevance of differentiating between neuropathy and myopathy is still under debate. A small case series of ICU survivors suggested a better outcome for patients with CIM in contrast with CIP [27]. A previous larger retrospective trial did not show any difference in outcome between CIP and CIM [28], and a recent systematic review (though not including the data of Guarneri and colleagues [27]) found insufficient data to confirm this [29].

Different changes in muscle histomorphology can be recognised. Three subtypes of acute myopathy of intensive care have been described [30] and are often grouped together as so-called 'acute quadriplegic myopathy': (a) diffuse non-necrotising 'cachectic' myopathy, (b) thickfilament myopathy or myopathy with selective loss of thick (myosin) filaments, and (c) acute necrotising myopathy. Nonnecrotising myopathy is accompanied by abnormal variation of muscle fibre size, fibre atrophy, predominantly type II fibres, angulated fibres, internalised nuclei, rimmed vacuoles, fatty degeneration of muscle fibres, and fibrosis. Type II fibre atrophy, however, is also reported in neuropathy and disuse atrophy. In thick-filament myopathy, a selective loss of myosin filaments is the predominant finding. This diagnosis requires the use of electron microscopy. Acute necrotising myopathy of critical illness is characterised by prominent myonecrosis, with vacuolisation and phagocytosis of muscle fibres, visible on optical microscopy as sparse, diffuse, or massive lesions. In a minority of the patients, this disease can progress to frank rhabdomyolysis [14,31,32]. Although muscle biopsy remains the diagnostic method of choice for detection of structural abnormalities, it remains invasive and therefore is not a practical screening tool. However, using biopsy and direct muscle stimulation, it has been recognised that the incidence of CIM is much higher than previously thought and many patients might even have a combination of CIP and CIM $[15,16,33,34]$.

Apart from the difficulties in differentiating CIP and CIM, they frequently co-occur. Electrophysiological and histological examination of patients indeed showed a significant overlap of CIP and CIM [15,17]. This has led to an often descriptive terminology in the literature, including terms such as 'ICUacquired paresis' and 'acquired neuromuscular disorders'. From a clinical point of view, CIP and CIM are often treated as a group and therefore are designated as critical illness polyneuromyopathy, critical illness neuromyopathy, or critical illness polyneuropathy and myopathy (CIP/CIM) [14,33,35,36].

\section{Incidence}

The incidence rates reported depend on the specific ICU subpopulation that is studied, the risk factors to which this population was exposed, the diagnostic criteria used, and the timing of diagnosis during the acute illness [37]. In sepsis or systemic 
inflammatory response syndrome (SIRS), $70 \%$ of patients develop CIP [10]. When further complicated by multiple organ failure (MOF), the incidence increases to up to $100 \%$ [18]. Importantly, critically ill comatose patients may become completely paralysed due to CIP/CIM [15]. Similarly, about $60 \%$ of patients with acute respiratory distress syndrome (ARDS) suffer from this disease [38]. In unselected patients receiving mechanical ventilation for at least 4 to 7 days, the occurrence of CIP/CIM was noticed to be $25 \%$ to $33 \%$ on clinical evaluation $[12,36,39]$ and up to $58 \%$ on electrophysiological evaluation [40-42]. Of patients in the ICU for at least 7 days, $49 \%$ to $77 \%[21,43,44]$ will acquire CIP/CIM. A neuromuscular disorder with a predominant muscle component (CIM) develops in at least one third of ICU patients treated for status asthmaticus [45], 7\% of patients after orthotopic liver transplantation [46], $38 \%$ of critically ill patients [33], and $68 \%$ of patients in the ICU for at least 7 days [21].

\section{Short-term and long-term implications}

CIP and CIM have an important impact on the outcome of patients in the ICU. They typically cause muscle weakness and paralysis and impair rehabilitation [42] in up to $100 \%$ of patients staying in the ICU for at least 4 weeks [47]. CIP/CIM itself may prolong the need for ventilatory support $[39,41,43$, $44,48]$ as the phrenic nerve and diaphragmatic muscle can be involved [10]. Not surprisingly, the duration of weaning in these patients is increased 2 to 7 times $[10,33,39,41,49]$. $\mathrm{CIP} / \mathrm{CIM}$ is associated with increased ICU and hospital stays $[41,49]$ and elevated mortality rates $[41,42,49,50]$, although other data suggest that patient selection may partially explain this [20]. Improvement occurs within weeks in mild cases and within months in severe cases. This recovery is characterised by progressive reinnervation of muscle and, in CIP, restoration of sensory function. Full recovery has been reported in over $50 \%$ of patients [10,29,51]. However, in the more severe cases, recovery may be incomplete or may not even occur at all $[1,10,47]$. A systematic review [29] reported severe disability impeding independent walking or spontaneous ventilation in $28 \%$ of patients, although this figure may be high due to the limited follow-up period in several case series. A small case series suggests that undetectable CMAPs could be a predictor of prolonged functional disability [52]. In patients recovering from ARDS, persistent functional limitation due to muscle wasting and weakness 1 year after discharge was noted in all patients [53]. Clinical and neurophysiological signs may remain present for up to 5 years after ICU discharge [47]. In the most severe cases, up to $32 \%$ are reported to remain severely disabled with tetraparesis, tetraplegia, or paraplegia [51]. Persistent milder disabilities are common even in patients with complete functional recovery, and in a small case series impaired quality of life after 1 year was frequently present in survivors [54].

\section{Risk factors}

A large number of studies have been performed to identify patients at risk for CIP/CIM. Among these, both prospective and retrospective trials have repeatedly identified sepsis, SIRS, and MOF as crucial risk factors. Also, the central role of MOF in the pathophysiology has been confirmed in a recent systematic review [37] and in a prospective cohort study [20]. Data reported on a number of other factors, such as hypoxia [55], hypotension [56], hyperpyrexia [57], and age [38], are not always consistent. Aminoglycosides have received particular attention as two studies associated their use with CIP $[40,42]$. However, other authors could not confirm these findings $[10,12,38,43,44,49,58]$, and therefore it seems that any association is not likely to be causal. The following factors have been identified as independent risk factors in prospective studies: female gender [12], severity of illness $[33,36]$, duration of organ dysfunction [12], renal failure and renal replacement therapy [49], hyperosmolality [49], parenteral nutrition [49], low serum albumin [10], duration of ICU stay $[10,43]$, vasopressor and catecholamine support [43], and central neurologic failure [49]. Hyperglycemia also has been identified as an independent risk factor [10,43], with an important potential impact in terms of prevention (see 'Prevention and therapy' section).

The impact of corticosteroids (CSs) on neuromuscular function in the ICU has been the subject of controversy. Many reports have found CIM to occur in patients treated with a combination of CSs and neuromuscular blocking agents (NMBAs). The myopathy that occurs in these patients mostly treated for severe asthma, chronic obstructive pulmonary disease, solid organ transplantation, leukemia, or lymphoma is most commonly a thick-filament myopathy. However, four prospective studies in unselected ICU populations could not identify CSs as an independent risk factor for CIP [49] or CIP/CIM [33,36,43], although three other prospective trials on weakness did [12,46,53]. In one study, CSs were even found to be an independent protective factor for the occurrence of CIP/CIM [44]. Similarly, four prospective trials did not identify NMBAs as an independent risk factor for CIP or CIP/CIM $[12,33,36,43]$, but two other trials did $[44,49]$. As $\mathrm{CIM}$ has been reported in patients receiving only one of these agents or receiving neither, it is clear that these drugs are not critical or essential in order to develop CIP/CIM.

\section{Pathophysiology}

The pathophysiology of CIP and CIM is complex and still unclear. A schematic overview is shown in Figure 1 [59]. The association between CIP/CIM and other organ failures has raised the question as to whether neuromuscular involvement is not simply a part of a systemic critical illness, representing just another organ failure. Bolton and colleagues $[10,60]$ hypothesised that sepsis-related disturbance of the microcirculation in peripheral nerves and muscles is a crucial event in the pathogenesis. In CIP, this may be mediated by the enhanced expression of E-selectin in the vascular endothelium of the peripheral nerves, induced by pro-inflammatory cytokines [61]. Hyperglycemia also may impair the microcirculation to the peripheral nerve. Moreover, cytokines 


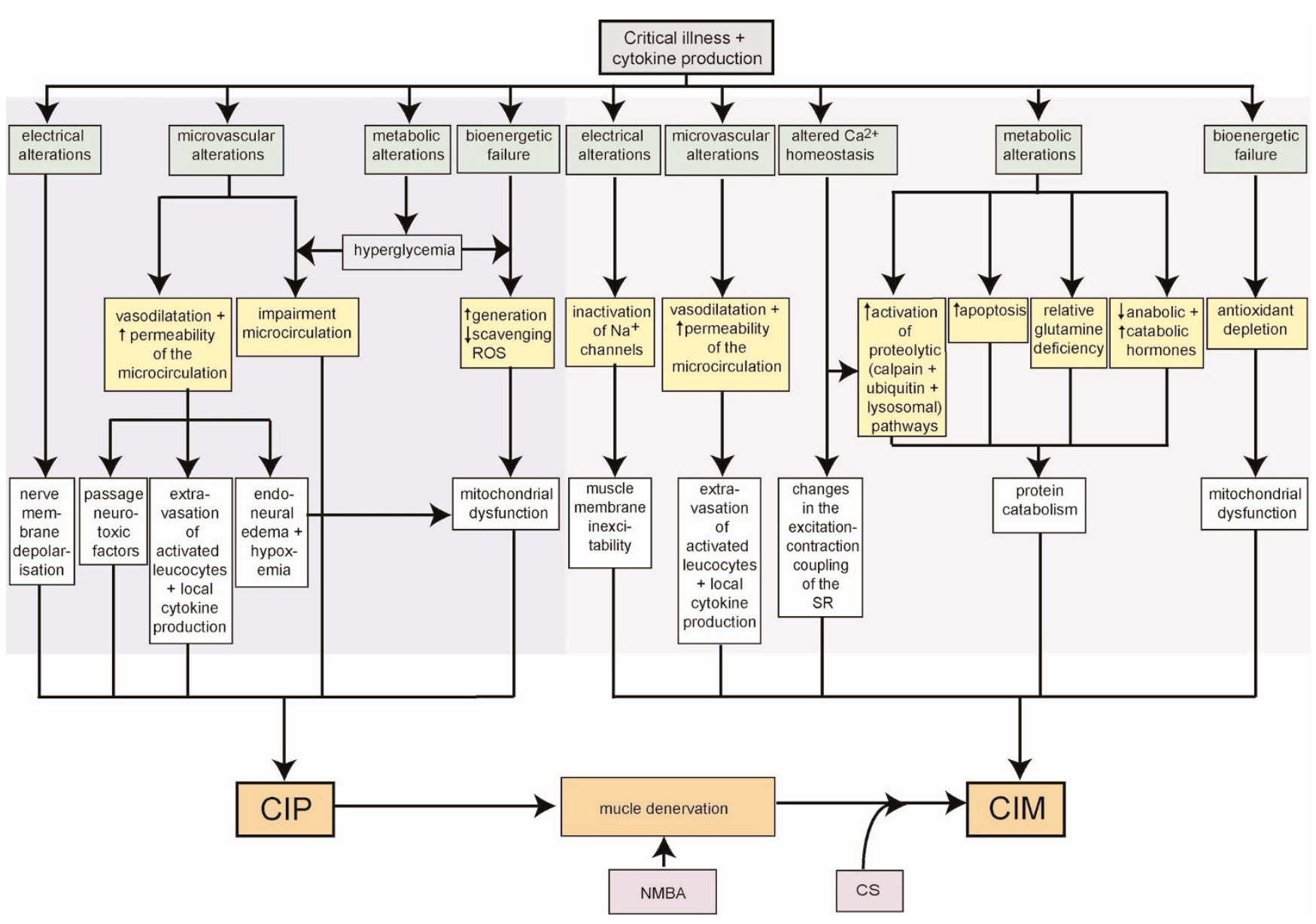

Presumed pathophysiological mechanisms and their interactions involved in the development of critical illness polyneuropathy/critical illness myopathy (CIP/CIM). CS, corticosteroids; NMBA, neuromuscular blocking agent; ROS, reactive oxygen species; SR, sarcoplasmatic reticulum.

secreted in sepsis have histamine-like properties that may increase microvascular permeability [60]. The resulting endoneural oedema could induce hypoxemia and energy depletion by increasing intercapillary distance and other mechanisms. Severe energy deficits would result, inducing primary axonal degeneration. Passive uptake of glucose with increased generation and deficient scavenging of reactive oxygen species could contribute to bioenergetic failure. Increased permeability may also enhance the passage of neurotoxic factors in the endoneurium and promote endothelial cell-leucocyte adhesion and extravasation of activated leucocytes within the endoneurial space, where they can induce tissue injury with local cytokine production [61]. Also, some cytokines may have direct toxic effects on peripheral nerves. A possible role for a neurotoxic factor in the pathogenesis of CIP has been suggested [62].

The pathophysiology of CIM is also complex, involving metabolic, inflammatory, and bioenergetic alterations. Protein catabolism and muscle wasting are observed in CIM. Proteolytic pathways involving calpain [63] and the ubiquitin-proteasome pathway $[64,65]$ are upregulated due to pro-inflammatory cytokines in conjunction with increased apoptosis [66]. As calpain is a calcium-activated protease, altered cellular calcium homeostasis due to endotoxemia and inflammation might play a role $[60,67]$. Also, acute stimulation of the TGF$\beta /$ MAPK (transforming growth factor-beta/mitogen-activated protein kinase) pathway following stress stimuli has been suggested to explain the muscle loss, coupled with the activation of the ubiquitin-proteasome pathway [68]. Muscle biopsies in these patients demonstrate a decrease in total amino acid concentration and, most strikingly, the glutamine levels [69]. Glutamine is known to stimulate protein synthesis and inhibit protein breakdown. There appears to be a relative deficiency of glutamine to increased demands in critical illness. Decreased levels of anabolic hormones and increased levels of catabolic hormones may contribute to myofilament loss and apoptosis in CIM [31]. Channelopathy is another mechanism that has been suggested in the pathophysiology. Electrodiagnostic studies often show evidence of muscle 
membrane inexcitability. This may be related to the inactivation of sodium channels at the resting potential and a shift in the voltage dependence of channel inactivation [70-73]. Interaction of lipopolysaccharide with voltage-gated sodium channels may contribute to muscle membrane inexcitability in sepsis [74]. Also, altered expression of nitric oxide synthetases has been suggested to possibly affect muscle membrane excitability in CIM as nitric oxide takes part in the maintenance of muscle fibre resting potential [75]. CIM may include alterations in the excitation-contraction coupling as blood sera from patients with CIM were found to affect not only the excitability of muscle fibre membranes but also the release of calcium from the sarcoplasmatic reticulum (SR) [76]. Evidence for these mechanisms and a possible 'myotoxic' factor responsible for this comes from animal data in which sera of patients with CIM had differential effects on resting and action potentials, sodium channels, and the excitation-contraction coupling process at the level of the SR$\mathrm{Ca}^{2+}$ release [76]. Nitric oxide overproduction, antioxidant depletion, mitochondrial dysfunction, muscle ATP depletion, and bioenergetic failure due to damage or inhibition of complex I of the respiratory chain may also be important [77]. The exact role of CSs and NMBAs in CIM is not clearly understood. Interestingly, in experimental models, muscle changes are prevented by concomitant administration of RU38486, a muscle CS receptor antagonist [78], suggesting that sepsis-induced muscle changes are mediated, at least partly, by endogenous CSs. Bolton [60] hypothesised that increased capillary permeability due to sepsis-induced release of cytokines allows NMBAs to cross the membrane and have direct toxic effects on the nerve or cause functional denervation of muscle, thereby possibly facilitating toxic effects of CSs or inflammatory mediators.

Functional denervation resulting from nerve injury in CIP may provide the link between CIP and CIM. Experimental CSinduced muscle alterations are significantly enhanced by limb denervation prior to exposure to CSs, suggesting that, in ICU patients, the axonal component of CIP/CIM or a chemical denervation such as induced by neuromuscular blockers could increase muscle susceptibility to CSs [79]. Another hypothesis is that both CIP and CIM represent different manifestations of a single pathologic mechanism in which sepsis triggers electrical inexcitability of the nerve, the muscle [80], and even the heart and central nervous system [81]. Also, evidence for a role of immune mechanisms in patients with $\mathrm{CIP} / \mathrm{CIM}$ exists. Indeed, small numbers of activated leucocytes producing pro- and anti-inflammatory cytokines infiltrate the skeletal muscle of patients with CIP/CIM [34].

Whereas most studies have focused on limb muscles, new data have shed light on some of the mechanisms of the diaphramatic muscle involvement. Diaphragm immobilisation in animal models under mechanical ventilation for only 18 hours induces a significant decrease in diaphragmatic force coupled with muscle atrophy and an increase in muscle markers of oxidative stress and calpain and ubiquitin-proteasome proteolytic activity [82], enhanced by NMBAs [83], and prevented by intermittent spontaneous breathing [84] and antiproteases [85]. Similar functional and histochemical diaphragmatic changes have been reported in animals submitted to experimental sepsis [86]. Preliminary human data suggest that the combination of 18 to 69 hours of complete diaphragmatic inactivity and mechanical ventilation results in marked atrophy of human diaphragm myofibres. These findings are consistent with increased diaphragmatic proteolysis during inactivity [87].

\section{Prevention and therapy}

As CIP/CIM not only has immediate detrimental effects in causing weaning difficulties but also causes long-term problems due to prolonged rehabilitation, it is a major cause of morbidity in patients surviving the acute phase of their critical illness. Until recently, only preventive measures consisting of reducing exposition to known risk factors and supportive measures were recommended in critically ill patients. Most authors agree on aggressive treatment of sepsis as the most important measure to reduce the incidence of CIP/CIM. CSs and NMBAs, if indicated, should be used at a minimal dose for as short a period as possible. Managing difficulty in weaning from mechanical ventilation [88] as well as rehabilitation programs [89] and avoiding additional pressure neuropathies by careful positioning are also considered to be major issues.

Several specific therapies have been mentioned as theoretically interesting and therefore potentially beneficial to prevent CIP/CIM. These include nutrition schemes and nutritional interventions [1], supplement therapies [90], antioxidant therapy [91], and the use of testosterone derivates [92], growth hormone [93], and immunoglobulins [58]. None of these, however, has actually been shown to have beneficial effects on muscle function in ICU patients.

Recently, the effect of intensive insulin therapy on CIP/CIM and the need for prolonged mechanical ventilation have been studied in surgical (SICU) and medical (MICU) ICU populations. Interest in this therapy was generated by the fact that hyperglycemia was associated with CIP/CIM by Witt and colleagues in 1991 [10], a finding that was confirmed by other investigators [12]. Avoiding hyperglycemia using insulin therapy to maintain strict glycemic control therefore may be beneficial to prevent CIP/CIM. Insulin itself has some potential beneficial effects, including anti-inflammatory effects [94], endothelial protection [95], improvement of dyslipemia, and neuroprotective effects in animals [96], and is also an anabolic hormone. Two prospectively planned subanalyses $[43,44]$ of two large randomised controlled trials $[97,98]$ were performed. The trials evaluated the effect of intensive insulin therapy on a SICU and a MICU (aiming at glycemia of 80 to $110 \mathrm{mg} / \mathrm{dL}$ ) versus conventional insulin therapy in which insulin was started when glycemia rose above 
$220 \mathrm{mg} / \mathrm{dL}$ and tempered or stopped at values below $180 \mathrm{mg} / \mathrm{dL}$. In the subanalyses, intensive insulin therapy significantly reduced the incidence of CIP/CIM detected on systematic electrophysiological investigation in patients in the ICU for at least 1 week, from $49 \%$ to $25 \%$ in the SICU $(P<0.0001)$ and from $51 \%$ to $39 \%$ in the MICU $(P=0.02)$. Also, the need for prolonged mechanical ventilation, defined as mechanical ventilation for at least 2 weeks, was reduced from $42 \%$ to $32 \%$ in the SICU $(P=0.04)$ and from $47 \%$ to $35 \%$ in the MICU $(P=0.01)$. Multivariate analysis attributed the beneficial effect on CIP/CIM to glycemic control [43], whereas the beneficial effect on prolonged mechanical ventilation was due to the insulin dose and was not completely explained by the benefit on CIP/CIM [44]. Although a beneficial effect of intensive insulin therapy is present in patients in whom tight glucose control did not totally succeed in lowering glycemic levels to the preset goal (but rather to between 110 and $150 \mathrm{mg} / \mathrm{dL}$ ), the benefit on CIP/CIM as well as on mortality is most pronounced in the patients with the tightest control (80 to $110 \mathrm{mg} / \mathrm{dL}$ ) [99]. These results are derived from post hoc analysis and need to be confirmed. As the beneficial effects of intensive insulin therapy on ICU patients are currently derived from a single centre, these results await confirmation in a larger population. The methodology of electrophysiological diagnosis was limited by the fact that muscle membrane inexcitability was not detected. Further investigations are needed to evaluate the extent to which the significant benefits in terms of electrophysiological abnormalities in the form of spontaneous electrical activity translate into clinical benefits in terms of muscle strength and recovery of neuromuscular function at and after discharge from the ICU [100].

Finally, although the use of CSs is currently discouraged, they theoretically could be interesting as, first of all, survival benefit is present in some subgroups of ICU patients treated with CSs such as those with septic shock, ARDS, and acute asthma. Moreover, CSs in specific ICU settings may reduce the duration and severity of MOF, which is the crucial risk factor for CIP/CIM [101]. CSs indeed showed a preventive effect on CIP/CIM in one prospective trial [44], and in a second prospective trial a trend toward beneficial effect was noticed [43]. The three prospective trials that identified CSs as independent risk factors for acquired weakness in the ICU either did not report glycemia [51] or did not treat hyperglycemia $[12,46]$. Therefore, these detrimental effects possibly could be related to hyperglycemia rather than CSs. However, even in the trial identifying CSs as a protective factor for CIP/CIM, the use of CSs was identified as an independent risk factor for prolonged mechanical ventilation [44]. Explanations for this remain speculative. As the diagnosis of CIP/CIM was made (on average) on day 8 whereas prolonged mechanical ventilation was defined from day 14 onward, CSs may have a time-dependent effect on the neuromuscular system in critically ill patients characterised by a short-term protective effect and a long-term deleterious effect. Another explanation could be that precise identification of the muscular effect of CSs requires the use of more sophisticated electrophysiological techniques such as direct muscle stimulation. Further study is needed to unravel the probable complex effects and their underlying pathogenetic mechanisms.

\section{Conclusions}

Critically ill patients frequently develop CIP/CIM, which delays weaning, compromises rehabilitation, and is associated with increased hospital and ICU stays and increased mortality rates. Until recently, no therapeutic measures had been proven to affect its incidence, and apart from supportive treatment, the only preventive measure was aimed at controlling the most important risk factor, MOF, as best as possible. Recently, two trials in a single centre reported that intensive insulin therapy significantly reduced the electrophysiological incidence of CIP/CIM and the need for prolonged mechanical ventilation in patients in the ICU for at least 1 week. This beneficial effect was present in a surgical as well as a medical population. However, concerns about safety and risk for hypoglycemia and limitations of diagnostic methods used in these trials have been raised, and these results have not yet been confirmed in a larger population. Concerning the neuromuscular effects of CSs, the evidence remains conflicting. Further research should address these questions and investigate the pathophysiological mechanisms underlying this important clinical problem.

\section{Competing interests}

The authors declare that they have no competing interests.

\section{Acknowledgements}

$\mathrm{GH}$ is the recipient of a $\mathrm{PhD}$ fellowship from the Flanders Research Fund (FWO-Vlaanderen).

\section{References}

1. Bolton CF, Laverty DA, Brown JD, Witt NJ, Hahn AF, Sibbald WJ: Critically ill polyneuropathy: electrophysiological studies and differentiation from Guillain-Barre syndrome. J Neurol Neurosurg Psychiatry 1986, 49:563-573.

2. Zochodne DW, Bolton CF, Thompson RT, Driedger AA, Hahn AF, Gilbert JJ: Myopathy in critical illness. Muscle Nerve 1986, 9: 652.

3. Lacomis D, Zochodne DW, Bird SJ: Critical illness myopathy. Muscle Nerve 2000, 23:1785-1788.

4. Spitzer AR, Giancarlo T, Maher L, Awerbuch G, Bowles A: Neuromuscular causes of prolonged ventilator dependency. Muscle Nerve 1992, 15:682-686.

5. Faragher MW, Day BJ, Dennett X: Critical care myopathy: an electrophysiological and histological study. Muscle Nerve 1996, 19:516-518.

6. Williams S, Horrocks IA, Ouvrier RA, Gillis J, Ryan MM: Critical illness polyneuropathy and myopathy in pediatric intensive care: a review. Pediatr Crit Care Med 2007, 8:18-22.

7. Bolton CF, Gilbert JJ, Hahn AF, Sibbald WJ: Polyneuropathy in critically ill patients. J Neurol Neurosurg Psychiatry 1984, 47: 1223-1231.

8. Roelofs RI, Cerra F, Bielka N, Rosenberg L, Delaney J: Prolonged respiratory insufficiency due to acute motor neuropathy: a new syndrome? Neurology 1983, 33:240.

9. Zochodne DW, Bolton CF, Wells GA, Gilbert JJ, Hahn AF, Brown JD, Sibbald WA: Critical illness polyneuropathy. A complication of sepsis and multiple organ failure. Brain 1987, 110:819-841. 
10. Witt NJ, Zochodne DW, Bolton CF, Grand'Maison F, Wells G, Young GB, Sibbald WJ: Peripheral nerve function in sepsis and multiple organ failure. Chest 1991, 99:176-184.

11. Bolton CF, Young GB, Zochodne DW: The neurological complications of sepsis. Ann Neurol 1993, 33:94-100.

12. De Jonghe $B$, Sharshar T, Lefaucheur JP, Authier FJ, DurandZaleski I, Boussarsar M, Cerf C, Renaud E, Mesrati F, Carlet J, Raphaël JC, Outin H, Bastuji-Garin S; Groupe de Réflexion et d'Etude des Neuromyopathies en Réanimation: Paresis acquired in the intensive care unit: a prospective multicenter study. JAMA 2002, 288:2859-2867.

13. Kleyweg RP, van der Meche FG, Schmitz PI: Interobserver agreement in the assessment of muscle strength and functional abilities in Guillain-Barre syndrome. Muscle Nerve 1991, 14:1103-1109.

14. Pandit L, Agrawal A: Neuromuscular disorders in critical illness. Clin Neurol Neurosurg 2006, 108:621-627.

15. Latronico N, Fenzi F, Recupero D, Guarneri B, Tomelleri G, Tonin P, De Maria G, Antonini L, Rizzuto N, Candiani A: Critical illness myopathy and neuropathy. Lancet 1996, 347:1579-1582.

16. Khan J, Harrison TB, Rich MM, Moss M: Early development of critical illness myopathy and neuropathy in patients with severe sepsis. Neurology 2006, 67:1421-1425.

17. Bednarik J, Lukas Z, Vondracek P: Critical illness polyneuromyopathy: the electrophysiological components of a complex entity. Intensive Care Med 2003, 29:1505-1514.

18. Tennila A, Salmi T, Pettila V, Roine RO, Varpula T, Takkunen O: Early signs of critical illness polyneuropathy in ICU patients with systemic inflammatory response syndrome or sepsis. Intensive Care Med 2000, 26:1360-1363.

19. Cankayali I, Dogan YH, Solak I, Demirag K, Eris O, Demirgoren S, Moral AR: Neuromuscular deterioration in the early stage of sepsis in rats. Crit Care 2007, 11:R1.

20. Latronico N, Bertolini G, Guarneri B, Botteri M, Peli E, Andreoletti S, Bera P, Luciani D, Nardella A, Vittorielli E, Simini B, Candiani A: Simplified electrophysiological evaluation of peripheral nerves in critically ill patients: the Italian multi-centre CRIMYNE study. Crit Care 2007, 11:R11.

21. Coakley JH, Nagendran K, Yarwood GD, Honavar M, Hinds CJ: Patterns of neurophysiological abnormality in prolonged critical illness. Intensive Care Med 1998, 24:801-807.

22. Rich MM, Bird SJ, Raps EC, McCluskey LF, Teener JW: Direct muscle stimulation in acute quadriplegic myopathy. Muscle Nerve 1997, 20:665-673.

23. Trojaborg W, Weimer LH, Hays AP: Electrophysiologic studies in critical illness associated weakness: myopathy or neuropathy-a reappraisal. Clin Neurophysio/ 2001, 112:1586-1593.

24. Lefaucheur JP, Nordine T, Rodriguez P, Brochard L: Origin of ICU acquired paresis determined by direct muscle stimulation. $J$ Neurol Neurosurg Psychiatry 2006, 77:500-506.

25. Lacomis D, Giuliani MJ, Van Cott A, Kramer DJ: Acute myopathy of intensive care: clinical, electromyographic, and pathological aspects. Ann Neurol 1996, 40:645-654.

26. Stibler H, Edstrom L, Ahlbeck K, Remahl S, Ansved T: Electrophoretic determination of the myosin/actin ratio in the diagnosis of critical illness myopathy. Intensive Care Med 2003, 29:1515-1527.

27. Guarneri B, Bertolini G, Latronico N: Long-term outcome in patients with critical illness myopathy or neuropathy: the Italian multicentre CRIMYNE study. J Neurol Neurosurg Psychiatry 2008, 79:838-841.

28. Lacomis D, Petrella JT, Giuliani MJ: Causes of neuromuscular weakness in the intensive care unit: a study of ninety-two patients. Muscle Nerve 1998, 21:610-617.

29. Latronico N, Shehu I, Seghelini E: Neuromuscular sequelae of critical illness. Curr Opin Crit Care 2005, 11:381-390.

30. Hund E: Myopathy in critically ill patients. Crit Care Med 1999, 27:2544-2547.

31. Latronico N, Peli E, Botteri M: Critical illness myopathy and neuropathy. Curr Opin Crit Care 2005, 11:126-132.

32. Barohn RJ, Jackson CE, Rogers SJ, Ridings LW, McVey AL: Prolonged paralysis due to nondepolarizing neuromuscular blocking agents and corticosteroids. Muscle Nerve 1994, 17: 647-654.

33. Bednarik J, Vondracek P, Dusek L, Moravcova E, Cundrle I: Risk factors for critical illness polyneuromyopathy. J Neurol 2005, 252:343-351.
34. de Letter MA, van Doorn PA, Savelkoul HF, Laman JD, Schmitz PI, Op de Coul AA, Visser LH, Kros JM, Teepen JL, van der Meche FG: Critical illness polyneuropathy and myopathy (CIPNM): evidence for local immune activation by cytokine-expression in the muscle tissue. J Neuroimmuno/ 2000, 106:206-213.

35. van Mook WN, Hulsewe-Evers RP: Critical illness polyneuropathy. Curr Opin Crit Care 2002, 8:302-310.

36. de Letter MA, Schmitz PI, Visser LH, Verheul FA, Schellens RL, Op de Coul DA, van der Meche FG: Risk factors for the development of polyneuropathy and myopathy in critically ill patients. Crit Care Med 2001, 29:2281-2286.

37. Stevens RD, Dowdy DW, Michaels RK, Mendez-Tellez PA, Pronovost PJ, Needham DM: Neuromuscular dysfunction acquired in critical illness: a systematic review. Intensive Care Med 2007, 33:1876-1891.

38. Bercker S, Weber-Carstens S, Deja M, Grimm C, Wolf S, Behse F, Busch T, Falke KJ, Kaisers U: Critical illness polyneuropathy and myopathy in patients with acute respiratory distress syndrome. Crit Care Med 2005, 33:711-715.

39. De Jonghe B, Bastuji-Garin S, Sharshar T, Outin H, Brochard L: Does ICU-acquired paresis lengthen weaning from mechanical ventilation? Intensive Care Med 2004, 30:1117-1121.

40. Leijten FS, de Weerd AW, Poortvliet DC, De Ridder VA, Ulrich C, Harink-De Weerd JE: Critical illness polyneuropathy in multiple organ dysfunction syndrome and weaning from the ventilator. Intensive Care Med 1996, 22:856-861.

41. Garnacho-Montero J, Amaya-Villar R, Garcia-Garmendia JL, Madrazo-Osuna J, Ortiz-Leyba C: Effect of critical illness polyneuropathy on the withdrawal from mechanical ventilation and the length of stay in septic patients. Crit Care Med 2005, 33:349-354.

42. Leijten FS, Harinck-de Weerd JE, Poortvliet DC, de Weerd AW: The role of polyneuropathy in motor convalescence after prolonged mechanical ventilation. JAMA 1995, 274:1221-1225.

43. Van den Berghe G, Schoonheydt K, Becx P, Bruyninckx F, Wouters PJ: Insulin therapy protects the central and peripheral nervous system of intensive care patients. Neurology 2005, 64:1348-1353.

44. Hermans G, Wilmer A, Meersseman W, Milants I, Wouters PJ, Bobbaers H, Bruyninckx F, Van den Berghe G: Impact of intensive insulin therapy on neuromuscular complications and ventilator-dependency in MICU. Am J Respir Crit Care Med 2007, 175:480-489.

45. Douglass JA, Tuxen DV, Horne M, Scheinkestel CD, Weinmann M, Czarny D, Bowes G: Myopathy in severe asthma. Am Rev Respir Dis 1992, 146:517-519.

46. Campellone JV, Lacomis D, Kramer DJ, Van Cott AC, Giuliani MJ: Acute myopathy after liver transplantation. Neurology 1998, 50:46-53.

47. Fletcher SN, Kennedy DD, Ghosh IR, Misra VP, Kiff K, Coakley JH, Hinds CJ: Persistent neuromuscular and neurophysiologic abnormalities in long-term survivors of prolonged critical illness. Crit Care Med 2003, 31:1012-1016.

48. De Jonghe B, Bastuji-Garin S, Durand MC, Malissin I, Rodrigues $\mathrm{P}$, Cerf C, Outin H, Sharshar T: Respiratory weakness is associated with limb weakness and delayed weaning in critical illness. Crit Care Med 2007, 35:2007-2015.

49. Garnacho-Montero J, Madrazo-Osuna J, García-Garmendia JL, Ortiz-Leyba C, Jiménez-Jiménez FJ, Barrero-Almodóvar A, Garnacho-Montero MC, Moyano-Del-Estad MR: Critical illness polyneuropathy: risk factors and clinical consequences. A cohort study in septic patients. Intensive Care Med 2001, 27: 1288-1296.

50. De Jonghe B, Cook D, Sharshar T, Lefaucheur JP, Carlet J, Outin $\mathrm{H}$ : Acquired neuromuscular disorders in critically ill patients: a systematic review. Groupe de Reflexion et d'Etude sur les Neuromyopathies En Reanimation. Intensive Care Med 1998, 24:1242-1250.

51. de Seze M, Petit H, Wiart L, Cardinaud JP, Gaujard E, Joseph PA, Mazaux JM, Barat M: Critical illness polyneuropathy. A 2-year follow-up study in 19 severe cases. Eur Neurol 2000, 43:6169.

52. Kerbaul F, Brousse M, Collart F, Pellissier JF, Planche D, Fernan$\operatorname{dez}$ C, Gouin F, Guidon C: Combination of histopathological and electromyographic patterns can help to evaluate functional outcome of critical ill patients with neuromuscular weakness syndromes. Crit Care 2004, 8:R358. 
53. Herridge MS, Cheung AM, Tansey CM, Matte-Martyn A, DiazGranados N, Al Saidi F, Cooper AB, Guest CB, Mazer CD, Mehta S, Stewart TE, Barr A, Cook D, Slutsky AS; Canadian Critical Care Trials Group: One-year outcomes in survivors of the acute respiratory distress syndrome. N Engl J Med 2003, 348: 683-693.

54. van der Schaaf M, Beelen A, de Vos R: Functional outcome in patients with critical illness polyneuropathy. Disabil Rehabil 2004, 26:1189-1197.

55. Dussoix P, Chevrolet JC, Cox J, Pizzolato G, Magistris MR: Secondary neuromyopathies in a resuscitation unit [in French]. Réanimation Urgences 1993, 2:247-258.

56. Rivner MH, Kim S, Greenberg M, Swift TR: Reversible generalized paresis following hypertension: a new neurological entity. Neurology 1983, 33:164.

57. Wilmshurst PT, Treacher DF, Lantos PL, Wiles CM: Critical illness poly-neuropathy following severe hyperpyrexia. QJM 1995, 88:351-355

58. Mohr M, Englisch L, Roth A, Burchardi H, Zielmann S: Effects of early treatment with immunoglobulin on critical illness polyneuropathy following multiple organ failure and gramnegative sepsis. Intensive Care Med 1997, 23:1144-1149.

59. Hermans G, De Jonghe B, Bruyninckx F, Van den Berghe G: Interventions for preventing critical illness polyneuropathy and critical illness myopathy. (Protocol). Cochrane Database Syst Rev 2007, (4):CD006832.

60. Bolton CF: Neuromuscular manifestations of critical illness. Muscle Nerve 2005, 32:140-163.

61. Fenzi F, Latronico N, Refatti N, Rizzuto N: Enhanced expression of E-selectin on the vascular endothelium of peripheral nerve in critically ill patients with neuromuscular disorders. Acta Neuropathol 2003, 106:75-82.

62. Hund $\mathrm{E}$, Herkert $\mathrm{M}$, Becker $\mathrm{CM}$, Hacke W: A humoral neurotoxic factor in sera of patients with critical illness polyneuropathy. Ann Neurol 1997, 40:539.

63. Showalter CJ, Engel AG: Acute quadriplegic myopathy: analysis of myosin isoforms and evidence for calpain-mediated proteolysis. Muscle Nerve 1997, 20:316-322.

64. Tiao G, Hobler S, Wang JJ, Meyer TA, Luchette FA, Fischer JE, Hasselgren PO: Sepsis is associated with increased mRNAs of the ubiquitin-proteasome proteolytic pathway in human skeletal muscle. J Clin Invest 1997, 99:163-168.

65. Klaude M, Fredriksson K, Tjader I, Hammarqvist F, Ahlman B, Rooyackers $\mathrm{O}$, Wernerman J: Proteasome proteolytic activity in skeletal muscle is increased in patients with sepsis. Clin Sci (Lond) 2007, 112:499-506.

66. Di Giovanni S, Mirabella M, D'Amico A, Tonali P Servidei S: Apoptotic features accompany acute quadriplegic myopathy. Neurology 2000, 55:854-858.

67. Wagenmakers AJ: Muscle function in critically ill patients. Clin Nutr 2001, 20:451-454.

68. Di Giovanni S, Molon A, Broccolini A, Melcon G, Mirabella M, Hoffman EP, Servidei S: Constitutive activation of MAPK cascade in acute quadriplegic myopathy. Ann Neurol 2004, 55: 195-206.

69. Gamrin L, Andersson K, Hultman E, Nilsson E, Essen P, Wernerman J: Longitudinal changes of biochemical parameters in muscle during critical illness. Metabolism 1997, 46:756-762.

70. Rich MM, Pinter MJ: Crucial role of sodium channel fast inactivation in muscle fibre inexcitability in a rat model of critical illness myopathy. J Physio/ 2003, 547:555-566.

71. Filatov GN, Rich MM: Hyperpolarized shifts in the voltage dependence of fast inactivation of Nav1.4 and Nav1.5 in a rat model of critical illness myopathy. J Physiol 2004, 559:813820.

72. Rossignol B, Gueret G, Pennec JP, Morel J, Giroux-Metges MA, Talarmin H, Arvieux CC: Effects of chronic sepsis on the voltage-gated sodium channel in isolated rat muscle fibers. Crit Care Med 2007, 35:351-357.

73. Allen DC, Arunachalam R, Mills KR: Critical illness myopathy: further evidence from muscle-fiber excitability studies of an acquired channelopathy. Muscle Nerve 2008, 37:14-22.

74. Haeseler G, Foadi N, Wiegand E, Ahrens J, Krampfl K, Dengler R, Leuwer M: Endotoxin reduces availability of voltage-gated human skeletal muscle sodium channels at depolarized membrane potentials. Crit Care Med 2008, 36:1239-1247.

75. Capasso M, Di Muzio A, Pandolfi A, Pace M, Di Tomo P, Ragno
M, Uncini A: Possible role for nitric oxide dysregulation in critical illness myopathy. Muscle Nerve 2008, 37:196-202.

76. Friedrich $\mathrm{O}$, Hund $\mathrm{E}$, Weber $\mathrm{C}$, Hacke $\mathrm{W}$, Fink $\mathrm{RH}$ : Critical illness myopathy serum fractions affect membrane excitability and intracellular calcium release in mammalian skeletal muscle. J Neuro/ 2004, 251:53-65.

77. Brealey D, Brand M, Hargreaves I, Heales S, Land J, Smolenski R, Davies NA, Cooper CE, Singer M: Association between mitochondrial dysfunction and severity and outcome of septic shock. Lancet 2002, 360:219-223.

78. Tiao G, Fagan J, Roegner V, Lieberman M, Wang JJ, Fischer JE, Hasselgren PO: Energy-ubiquitin-dependent muscle proteolysis during sepsis in rats is regulated by glucocorticoids. J Clin Invest 1996, 97:339-348.

79. Massa R, Carpenter S, Holland P, Karpati G: Loss and renewal of thick myofilaments in glucocorticoid-treated rat soleus after denervation and reinnervation. Muscle Nerve 1992, 15: 1290-1298.

80. Z'Graggen WJ, Lin CS, Howard RS, Beale RJ, Bostock H: Nerve excitability changes in critical illness polyneuropathy. Brain 2006, 129:2461-2470.

81. Teener JW, Rich MM: Dysregulation of sodium channel gating in critical illness myopathy. J Muscle Res Cell Motil 2006, 27: 291-296.

82. Shanely RA, Zergeroglu MA, Lennon SL, Sugiura T, Yimlamai T, Enns D, Belcastro A, Powers SK: Mechanical ventilationinduced diaphragmatic atrophy is associated with oxidative injury and increased proteolytic activity. Am J Respir Crit Care Med 2002, 166:1369-1374.

83. Testelmans D, Maes K, Wouters P, Powers SK, Decramer M, Gayan-Ramirez $\mathrm{G}$ : Infusions of rocuronium and cisatracurium exert different effects on rat diaphragm function. Intensive Care Med 2007, 33:872-879.

84. Gayan-Ramirez G, Testelmans D, Maes K, Racz GZ, Cadot P, Zador E, Wuytack F, Decramer M: Intermittent spontaneous breathing protects the rat diaphragm from mechanical ventilation effects. Crit Care Med 2005, 33:2804-2809.

85. Maes K, Testelmans D, Powers S, Decramer M, Gayan-Ramirez G: Leupeptin inhibits ventilator-induced diaphragm dysfunction in rats. Am J Respir Crit Care Med 2007, 175:1134-1138.

86. Fujimura N, Sumita S, Narimatsu E, Nakayama Y, Shitinohe Y, Namiki A: Effects of isoproterenol on diaphragmatic contractility in septic peritonitis. Am J Respir Crit Care Med 2000, 161: 440-446.

87. Levine S, Nguyen T, Taylor N, Friscia ME, Budak MT, Rothenberg P, Zhu J, Sachdeva R, Sonnad S, Kaiser LR, Rubinstein NA, Powers SK, Shrager JB: Rapid disuse atrophy of diaphragm fibers in mechanically ventilated humans. N Engl J Med 2008, 358:1327-1335.

88. Boles JM, Bion J, Connors A, Herridge M, Marsh B, Melot C, Pearl $\mathrm{R}$, Silverman H, Stanchina M, Vieillard-Baron A, Welte T: Weaning from mechanical ventilation. Eur Respir J 2007, 29:1033-1056.

89. Martin UJ, Hincapie L, Nimchuk M, Gaughan J, Criner GJ: Impact of whole-body rehabilitation in patients receiving chronic mechanical ventilation. Crit Care Med 2005, 33:2259-2265.

90. Berard MP, Zazzo JF, Condat P, Vasson MP, Cynober L: Total parenteral nutrition enriched with arginine and glutamate generates glutamine and limits protein catabolism in surgical patients hospitalized in intensive care units. Crit Care Med 2000, 28:3637-3644.

91. Yu YM, Ryan CM, Fei ZW, Lu XM, Castillo L, Schultz JT, Tompkins RG, Young VR: Plasma L-5-oxoproline kinetics and whole blood glutathione synthesis rates in severely burned adult humans. Am J Physiol Endocrinol Metab 2002, 282:E247-E258.

92. Schols AM, Soeters PB, Mostert R, Pluymers RJ, Wouters EF: Physiologic effects of nutritional support and anabolic steroids in patients with chronic obstructive pulmonary disease. A placebo-controlled randomized trial. Am J Respir Crit Care Med 1995, 152:1268-1274.

93. Pichard C, Kyle U, Chevrolet JC, Jolliet P, Slosman D, Mensi N, Temler E, Ricou B: Lack of effects of recombinant growth hormone on muscle function in patients requiring prolonged mechanical ventilation: a prospective, randomized, controlled study. Crit Care Med 1996, 24:403-413.

94. Hansen TK, Thiel S, Wouters PJ, Christiansen JS, Van den Berghe $\mathrm{G}$ : Intensive insulin therapy exerts antiinflammatory effects in critically ill patients and counteracts the adverse effect of low 
mannose-binding lectin levels. J Clin Endocrinol Metab 2003, 88:1082-1088.

95. Langouche L, Vanhorebeek I, Vlasselaers D, Vander Perre S, Wouters PJ, Skogstrand K, Hansen TK, Van den Berghe G: Intensive insulin therapy protects the endothelium of critically ill patients. J Clin Invest 2005, 115:2277-2286.

96. Ishii DN, Lupien SB: Insulin-like growth factors protect against diabetic neuropathy: effects on sensory nerve regeneration in rats. J Neurosci Res 1995, 40:138-144.

97. Van den Berghe G, Wouters P, Weekers F, Verwaest C, Bruyninckx $F$, Schetz M, Vlasselaers $D$, Ferdinande $P$, Lauwers $P$, Bouillon R: Intensive insulin therapy in the critically ill patients. $N$ Engl J Med 2001, 345:1359-1367.

98. Van den Berghe G, Wilmer A, Hermans G, Meersseman W, Wouters PJ, Milants I, Van Wijngaerden E, Bobbaers H, Bouillon $\mathrm{R}$ : Intensive insulin therapy in the medical ICU. $N$ Engl J Med 2006, 354:449-461.

99. Van den Berghe G, Wilmer A, Milants I, Wouters PJ, Bouckaert B, Bruyninckx F, Bouillon R, Schetz M: Intensive insulin therapy in mixed medical/surgical intensive care units: benefit versus harm. Diabetes 2006, 55:3151-3159.

100. De Jonghe B, Finfer S: Critical illness neuromyopathy: from risk factors to prevention. Am J Respir Crit Care Med 2007, 175:424-425.

101. Annane D, Bellissant E, Bollaert PE, Briegel J, Keh D, Kupfer Y: Corticosteroids for treating severe sepsis and septic shock. Cochrane Database Syst Rev 2004, (1):CD002243. 